\title{
Making Knowledge in Boundary Infrastructures: Inside and Beyond a Database for Rare Diseases
}

\author{
Éric Dagiral \\ Université Paris Descartes, CERLIS, Sorbonne Paris Cité, France / eric.dagiral@parisdescartes.fr
}

\author{
Ashveen Peerbaye \\ LISIS, Université Paris-Est, France
}

\begin{abstract}
This paper provides an ethnographical study of the ways in which infrastructure matters in the production of knowledge in the social worlds of rare diseases. We analyse the role played by a relational database in this respect, which exists at the crossroads of a large and complex network of individuals, institutions, and practices. This database forms part of a "boundary infrastructure", in which knowledge production constitutes one output of infrastructural work, that needs to be articulated with other kinds of activities and matters of concern. We analyse how members of the network negotiate the place and forms of knowledge production in relation to these other purposes, and highlight the political nature of the distinction between knowledge and information, which frames collective action. We also show how infrastructural inversion serves to articulate knowledge production with other forms of mobilisation, thereby shaping and reconfiguring the boundary infrastructure as a whole.
\end{abstract}

Keywords: knowledge infrastructures, boundary infrastructures, relational databases, rare diseases

\section{Introduction}

This paper provides a conceptualisation of the role played by infrastructure in the production of knowledge on human rare diseases. Despite the rarity of individual cases, about 30 million persons living in Europe today are estimated to suffer from one of these disorders, of which over 6000 have been identified, with many being early-onset, chronic, degenerative and invalidating conditions. Individuals and organisations exposed to rare diseases (e.g. patients and their relatives, physicians, scientists, healthcare professionals) have to face situations in which the lack of knowledge heavily hampers diagnosis, referrals to specialists, medical care provision, as well as clinical and therapeutic research. Over the last three decades, scientific research centres, medical and healthcare organisations, pharmaceutical industrialists, public health institutions and patient advocacy groups have gathered into a heterogeneous network devoted to the cause of rare diseases (Huyard, 2012). In France and elsewhere in Europe these various actors have gradually begun to cooperate (frequently without consensus) in order to gather resources, align political agen- 
das, and manage a large and ever-extending variety of projects related to rare diseases. Some of these projects aim to foster biomedical research in order to document epidemiological, clinical and genetic aspects of understudied diseases and disorders. Other projects strive to gather and distribute scarce information to healthcare organisations, professionals, or the general public. Still others work for the promotion of orphan drug development by the pharmaceutical industry, or the empowerment of patients and their relatives, for instance through the building of online communities, participation in clinical trials, and struggle for equal access to available treatment and healthcare. These patterns of cooperation across the network have come to rely ever more heavily upon an array of work routines and tools, such as online databases, diagnostic expert systems, classification systems, indexes, registries and so on. This set of distributed technical, informational and organisational resources constitutes an infrastructure that now shapes ways of knowing, working and living with rare diseases.

Recent scholarship in STS adopts a broad definition of infrastructure and highlights their crucial role in the production of knowledge. Bowker et al. (2010: 98) suggest envisioning knowledge infrastructures as "pervasive enabling resources in network form" that allow "knowledge work" to be performed. This definition departs from the conventional representation of infrastructure as a mere machinery of "tubes and wires", to include a wide range of technologies and organisations that span large-scale sites and instruments devoted to scientific research (e.g. "supercolliders, orbiting telescopes, supercomputer centres, polar research stations, national laboratories"), institutional and technological structures that buttress the functioning of science ("funding agencies, professional societies, libraries and databases, scientific publishing houses, review systems, and so on"), as well as the various users, mediators and professionals that are involved in the design, implementation, and management of shared digital services and resources ("data and code repositories, best practices and standards development, visualisation tools and high performance computing, and so on"). This definition is very illuminating since it provides a framework for analysing how infra- structure reconfigures work practices, and especially scientific work. Biomedical research and the life sciences have provided major fields of inquiry in this regard. The importance of genome databases in the "the canonical scientific act for our times (sequencing the genome)" (Bowker, 2005: 30) is for instance well documented. Studies of knowledge production regimes in the sciences highlight the increased reliance upon shared facilities and instrumentation, online digital databases, as well as standards for the publication and sharing of data and metadata (Millerand \& Bowker, 2009). These transformations are predicated on technologies, capacities and practices for storing, analysing, representing and circulating information. They modify the speed and scale at which these operations and exchanges take place. As Bowker and Star (1999: 108) argue "infrastructure does more than make work easier, faster or more efficient; it changes the very nature of what is understood by work." In the case of knowledge production, these transformations introduce novel forms of publication and validation of scientific results (Hilgartner, 1995), affect patterns of scientific collaboration (Parker et al., 2010) and ways of knowing (Strasser, 2011): they change the very nature of what is understood by knowledge.

A growing body of literature has started to take into account such infrastructural transformations - very often gathered under such labels as e-science, cyberscience or cyberinfrastructure in a large variety of disciplines, ranging from life sciences to ecology, biodiversity, earth and climate sciences, and the humanities (Miller \& Edwards, 2001; Hine, 2006b; Olson et al., 2008; Dutton \& Jeffreys, 2010). Social studies of databases are of particular importance in this respect. Bowker (2000) shows that the convergence of heterogeneous databases in biodiversity sciences raises the issue of how various social and political values might be embedded into the emerging infrastructure, and be made to coexist. Examining the development of a mouse genome mapping resource, Hine (2006a) argues that databases are more and more often configured and used as genuine research tools in their own right. Their mobilisation in the laboratory introduces additional mediations and challenges in the organisation and outcomes of knowledge work. The negotia- 
tion of rules for data entry, for instance, reveals the complex reorderings that such resources entail, and casts new light on the issue of cooperation in molecular biology as analysed by Knorr Cetina (1999: 234-240). Millerand (2011) in her study of a large-scale database devoted to arctic research, gathering geophysical, biological, medical and sociological data, pinpoints the differences in instrumental practices and the various significations attributed to data, and explores their impact on the division of scientific labor across disciplines and epistemic cultures. Leonelli provides an understanding of the ways in which "the worlds of data infrastructures and knowledge production inform each other" (Leonelli, 2013: 513), by foregrounding the role of data-sharing resources, such as databases, in the production of scientific evidence in contemporary biology. Her definition of data as material artifacts which are mobilised in relation to specific contexts of knowledge production captures the different modalities through which data integration is performed to produce new knowledge, according to a variety of goals, methods, strategies and norms (Leonelli, 2015).

Our own contribution aims to similarly emphasise the crucial ways in which infrastructural issues come to matter in the production of knowledge in the social worlds of rare diseases. Of particular importance here is the role played by a relational database devoted to rare diseases and orphan drugs, whose setting up, maintenance and use can be seen as a major achievement of the collectives involved. However, this database will be shown to exist at the crossroads of a large and complex network of individuals, institutions, and practices, in which the basis of collective mobilisation is quite blurry, and not centred at the outset on knowledge production - though undoubtedly the circulation and use of knowledge and information are crucial issues here for collective action. In contrast to situations where the production of knowledge, and especially scientific knowledge, is the core legitimate focus and outcome of the organisation of work (e.g. in laboratories, scientific collaborative networks, disciplinary or transdisciplinary research communities, etc.), our case provides a context in which the involvement of different communities extends well beyond this goal. The database forms part of a larger infrastructure, in which knowledge production constitutes one output of infrastructural work, that needs to be furthermore articulated with other kinds of activities and matters of concern. Bowker and Star (1999: 313) resort to the concept of "boundary infrastructure" to acknowledge these situations where "[an] infrastructure serves multiple communities of practice simultaneously, be these within a single organization or distributed across multiple organizations". They argue that "[what] we gain with the concept of boundary infrastructure over the more traditional unitary vision of infrastructures is the explicit recognition of the differing constitution of information objects within the diverse communities of practice that share a given infrastructure" (Bowker \& Star, 1999: 314). Our study takes up this concept and explores its practical and theoretical implications, by examining how members of the network negotiate the place and forms of knowledge production in relation to the other purposes they pursue in various collaborative projects. This leads us to put forward two main claims. The first has to do with the political nature of the distinction between knowledge and "mere" information, which lies at the very heart of many debates between actors. Here, this kind of boundary work (Gieryn, 1983) serves as a resource in strategies to embed competing visions and goals into the boundary infrastructure, define priorities, and allocate resources for carrying out different tasks related to rare disease initiatives. The second is that in order to negotiate the political, moral and epistemic dimensions of the boundary infrastructure they contribute to and rely on, actors resort to infrastructural inversion (Bowker, 1994): they discuss explicitly of the infrastructure itself, and strive to represent its inner workings, shortcomings and desirable evolutions. Infrastructural inversion, therefore, is not only a methodological lens for the analyst to capture how things like databases and classification systems are embedded in the many practices of collectives engaged in the field of rare diseases. It is also constitutive of the practices of these collectives themselves.

The arguments presented in this paper are grounded in extensive fieldwork carried out between 2007 and 2013, to explore the 
social worlds of rare diseases at the French and European levels. The authors jointly conducted a four-year ethnographic study of the "Rare Diseases Platform", a European-level entity created in the early 2000s, and located in Paris (France). The Platform itself is comprises of six distinct organisations: a data-based resource centre (Orphanet) belonging to the French Institute of Health and Medical Research; a help line devoted to providing support and information on rare diseases to the general public (Maladies Rares Info Services); a consortium for the funding and promotion of research and healthcare activities in the field of rare diseases (GIS-Institute for Rare Diseases); two patient-driven federations (Alliance Maladies Rares in France, and EURORDIS at the European level); and the French Muscular Dystrophy Association (AFM-Téléthon) which played a major part in gathering those organisations into a "platform" in the first place. During that period, we collected data from regular participant observation of individual and collective everyday work activities at Orphanet and MRIS (situations involving database manipulation, editorial activities, discussions at project meetings, maintenance work). We analysed various documents and work materials, including technical worksheets, reference documentation, meeting and activity reports, internal memos, and transcripts from electronic communications. We also regularly attended collective events in which the different members of the Platform gathered as a whole (board and committee meetings, scientific and associative events, annual March for Rare Diseases, etc.) In addition to everyday informal interactions, we conducted fifty semi-structured interviews with twenty-six team members and managing directors from these six organisations, focusing on aspects related to scientific and extrascientific collaboration, information gathering and exchange, and involvement in technological projects pertaining to infrastructure. Follow-up materials were gathered in 2011-2013, through thirteen interviews with database managers and technicians, and experts in health information systems involved in many of the Platform's projects. These focused mainly on the integration of novel web ontologies and standards into the Platform's existing infrastructure.
We begin by examining how the boundary between knowledge and information is negotiated inside the European Rare Diseases Platform and contributes to frame collective action. We then show that what counts as knowledge infrastructure and what counts in a knowledge infrastructure are materially enacted within a relational database. Finally, we move on beyond the database itself to reveal how infrastructural inversion serves to articulate knowledge production with other forms of mobilisation, thereby shaping and reconfiguring the boundary infrastructure as a whole.

\section{Negotiating the Boundary Between Knowledge and Information in the European Rare Diseases Platform}

\section{Knowing What Counts as Knowledge}

Issues related to knowledge production have been from the very outset a central concern for the different organisations that gathered together in the early 2000s to form the Rare Diseases Platform. The main challenge in this respect has been to articulate a framework taking into account a broad understanding of what constitutes "knowledge" in the social worlds of rare diseases, as well as securing and allocating resources for its production and mobilisation in concerted action. One aspect of this problem refers to the necessity of addressing the lack of biomedical knowledge on understudied low-prevalence diseases and disorders, by fostering scientific, discipline-based endeavours, in clinical research, experimental medicine and biology, epidemiology and so on. As one director of the French Muscular Dystrophy Association put it to us:

\footnotetext{
"In a field such as rare diseases, boundaries are more blurry than with common diseases. This is problematic because EU-funded research projects, for example, do not have the same rules for funding whether one is at the level of the Department of health or the Department of research. But, in the case of rare diseases you do not have health teams on side, and scientific research teams on the other. In the teams, you find both the research part mixed with the health part. In many cases, the clinician provides medical care, does fundamental research, is involved in information activities, etc.
} 
This integrated model corresponds to the way we wanted to function as a platform. The idea is that in order to make progress on such a topic, we need to advance in a systematic, global fashion, tackling things from all sides, provided that there is a minimum of coordination and consistency in our approaches."

However, construing knowledge as scientific knowledge alone was not deemed satisfactory to tackle the social problem posed by rare diseases. As the Platform progressively gained organisational and institutional reality, discussions between participants about knowledge issues and how to address them started to be framed through the broader motto of the "fight against ignorance":

“Managing to spell out these problems of social ignorance through the category of rare diseases was far from self-evident. It is true that genetics and science have contributed to build a collective vision of rare diseases. However, when the Platform was created, the actors' perception was that beyond the scientific aspect of [rare] diseases, we had to struggle in favour of populations whose existence was being denied from a medical, scientific but also civic standpoint, and who weren't being listened to. [...] Our goal was to build acceptance about the fact that this small minority of people and situations were included inside society, had rights as everybody else, and that there was a need for specific modalities to secure their exercise of these rights. [...] We had a strong commitment to bring about societal change, by using all the levers of modern information and communication." (French Muscular Dystrophy Association director)

In their discussions and negotiations to find common ground for collective action, "information" rather than "knowledge" quickly became the category of choice under which participants of the Platform framed their involvement and publicised their "fight against ignorance" of rare diseases. One of the main objectives of the Platform's programme officially became to "develop information on rare diseases for patients, health professionals and the general public", a priority which was integrated as such into national plans and strategies for rare diseases (notably the French National Plan on Rare Diseases in 2005, but also in Bulgaria, Por- tugal and Spain), as well as into the policy framework for rare diseases defined by the European Union Committee of Experts on Rare Diseases (Aymé \& Rodwell, 2013). For all parties involved, including the Platform's main funding institutions (AFM-Téléthon and the French Ministry of Health), resorting to the category of information better allowed to take into account the fact that their commitment exceeded the production of novel biomedical knowledge, and included knowledgerelated activities that were often not sanctioned as such by institutions: providing information about diseases for instance, or fostering relationships between hospitals, laboratories, companies and patients. This focus on information brought to the fore practical issues related to activities of gathering, consolidating, formatting, connecting and circulating heterogeneous resources across various communities. It also fostered a more "representational" vision of knowledge on rare diseases, understood as something that must not only be produced, but also be made visible and mediated in order for rare diseases to be recognised as a social problem in its multiple dimensions (Dagiral \& Peerbaye, 2012).

The trajectory of Orphanet, one of the Platform's main components devoted to information development, clearly exemplifies this strategy. The existence of Orphanet as an organisational entity predates its inclusion in the Platform. It was created in 1997 as a unit of the French National Institute of Health and Medical Research (Inserm), resulting from longstanding efforts (going back to the 1970s and 1980s) from the part of a handful of physicians and geneticists who were being confronted with diagnosis problems in cases encountered during consultations, for which documentation in the medical literature was very scarce or unavailable. These specialists strived to gather expertise, monitor the scientific literature and create classifications of these rare symptoms in a computerised form. One aspect of the creation of Orphanet therefore results from a clinical and scientific concern that at the same time encompassed a technological issue: creating from scratch a computer database that could be queried as an expert system to help establish diagnoses in infrequently encountered situations. Of course, as many authors studying 
infrastructures have pointed out, an infrastructure rarely ever springs ex nihilo, but rests upon an "installed base" of pre-existing elements, from which it inherits its strengths and limitations (Star \& Ruhleder, 1996: 113). In this case, these elements included paper documents piled up in bulky folders, punch cards, old computer programming languages such as Fortran, videodiscs, CD-ROMs and now-obsolete software applications (Dagiral \& Peerbaye, 2013). During the 1990s, and even more in the early 2000s, following its inclusion in the Rare Diseases Platform, Orphanet moved from a physician-oriented diagnostic expert system to a multi-purpose instrument central to the Platform's information development strategy. This materialised in particular through the setting up of a public web portal for rare diseases and orphan drugs, named Orphanet ${ }^{1}$, whose operation relied on a vast computerised relational database. Clearly, the system wasn't intended and designed at the outset to become the cornerstone of an overarching and ever-growing infrastructure supporting the activities of various organisations working in the field of rare diseases. It provided, however, the technological core around which different kinds of resources on rare diseases started to coalesce, in the guise of an online relational database warehousing very heterogeneous elements, to be articulated and used by multiple publics, in varied situations.

Orphanet is led today by a consortium of around 40 countries, coordinated by the French Inserm team. Teams in Europe and other parts of the world are responsible for gathering information on expert centres, medical laboratories, ongoing research and patient organisations in the field of rare diseases in their country, while the French coordinating team is responsible for the management of tools, standards and quality control procedures, but also provides rare disease inventories and classifications, and produces a rare diseases encyclopaedia. The "public" side of this initiative consists of the web portal, available in seven languages, which offers several types of resources aimed at patients and their families, patient organisations, as well as professionals - physicians, researchers, industry actors, and public health authorities. Starting with the definition of a disease and its clinical signs, the portal collates data related notably to epidemiological and genetic aspects, research projects, scientific publications, expert centres, diagnostic tests, clinical trials, and patient organisations associated with the given disease. In the early 2010s, this amounted to more than 6000 diseases or disorders, that existed on the "private" side as digital entities inside a relational database, on which different professionals intervened in order to update information, add newly identified diseases and resources, while also rethinking how all this information should be classified and interconnected, both from a cognitive and a technological perspective.

Orphanet's trajectory shares many characteristics with contemporary situations that may be encountered in a number of professional spheres. The digitisation of networks, the prevalence of databases, and the use of the Internet in everyday work inside or across organisations are common features that have introduced important reconfigurations in the distribution and collectivisation of tasks. They have brought a greater division of labour, changed how activities are measured and monitored, and increased the complexity of relationships between members of an organisation, as well as between organisations in cooperative work contexts.

\section{The Platform as Boundary Infrastructure}

It is tempting in our case to consider the Orphanet database and its interfaces (one of which is the web portal) as encapsulating the entire knowledge infrastructure of the Platform. This however would simply not be true. While the database was undeniably configured to function as a quasiobligatory passage point for producing information and representing knowledge on rare diseases, it does not constitute in and of itself the whole infrastructure. This is due to the fact that as Star and Ruhleder (1996) repeatedly remind us, infrastructure is a fundamentally relational phenomenon, not just something that "sits there": what is the daily work of one person is the infrastructure of another, what counts as an enabling infrastructure in one situation can become an obstacle in another. As a consequence, the perimeter of a knowledge infrastructure is not defined by its technical manifestation as a thing (a data- 
base, an online web portal, etc.) but by the shifting sociotechnical forms and organised practices that happen in situations of use across multiple communities of practice.

For an infrastructure to exist and function properly, investments are needed. Here, Laurent Thévenot's (1984) concept of "investment in form" proves analytically instrumental. As Keating and Cambrosio (2003: 38) have argued in the case of the establishment of biomedical platforms, the "reallocation of personnel and material entail[s] an investment in form that enable[s] previously heterogeneous equipment (in the largest sense of the term) to function together as a new sociotechnical unit". Thévenot (1984: 5-9) defines investment in form as "a costly operation to establish a stable relation with a certain lifespan", which can be performed through a "great variety of formatting operations, from the material constraint of standardization to the moral imperative of engagement, and the obligation of conventions":

"Conforming and informing both require and are preceded by acts of giving form. This is why an 'investment in form', which might rely on different 'formats of information' [...] is the keystone that joins 'regulation' and 'objectivity'. The returns on such an investment, in terms of coordination, vary according to three dimensions: the temporal and spatial validity of the form, and the solidity of the material equipment involved. Once an investment has been made, it will have a 'temporal validity': that is, the period of time in which it is operative in a community of users. It will also have a 'spatial validity', which refers to the boundaries demarcating the community within which the form will be valid. This is why participating in the process of form-giving can be a means to prevent a standard from becoming external to one's own concerns, and therefore, potentially exclusionary." (Thévenot, 2009: 794)

Thévenot (2009) provides an insightful framework, which ties together nicely many of the themes we try to stress in this study: 1) a sense of collective commitment that rests upon and allows for the possibility of coordination; 2) a world-building relationship between persons and organisations that relies on the production of categories of likeness, equivalence and homogeneity through specific relations to things and their transforma- tion; 3) a relation between "invested forms" and the engagement in specific modes of coordinated action they entail, which come to be deemed more effective, legitimate, desirable, and binding; 4) a certain disregard for the ordinarily assumed distinctions between cognitive, informational, technical and regulatory operations - understood as all partaking in the act of "giving form"; and 5) a focus on the characteristics of sustainability and the modalities of extension of the forms implemented.

A very relevant illustration of this process is provided by the use of the category of "platform" by members of the rare diseases community, in order to reflexively designate their engagement and modes of coordinated action. Indeed, this notion articulates a political commitment to a set of ideas and values with technical considerations, as well as spatial aspects (working together in connected spaces, whilst maintaining separate organisations and institutional arrangements):

\footnotetext{
"[In calling ourselves a platform] we were probably influenced in part by the logic of technological research. [...] At the same time, alongside building and managing collective logistics and sharing technological resources, there was a strong will to appear as one structure. What is important in appearing as a platform is showing how we believe things should be approached: globally, systematically, mobilising actors with major levels of responsibility and commitment." (French Muscular Dystrophy Association director)
}

This meaningful inscription in a shared physical space of distinct forms of expertise and matters of concern also rested ultimately on operations of investment in form as defined above. This is a fact most actors were reminded of on an almost daily basis during our fieldwork, since the Platform was in the process of being physically relocated from one building to another in a Parisian hospital. Tense negotiations ensued about the distribution not only of working space, but also of workload and responsibilities among the platform's various entities. At their very heart lay the highly practical modalities of collaboration needed to ensure that knowledge work could be productively mobilised to further other kinds of activities, such as providing information and counselling, putting patients 
in touch with various organisations, or support the advocacy of rare disease associations.

Bowker and Star (1999) propose the concept of "boundary infrastructure" to capture how any working infrastructure, far from constituting a monolithic unit, provides an evolving system of boundary objects which different communities of practice (distributed within and across organisations) can simultaneously "plug into" in order to collaborate, all the while maintaining just enough local variation and just enough global consistency across sites for various kinds of commitments to work in concert (Star \& Griesemer, 1989; Star, 2010). Envisioning the Rare Diseases Platform as an instantiation of such a boundary infrastructure is illuminating, since it puts to the fore the multiple, and sometimes competing, needs and visions that must be taken into account in order to "build and maintain productive relationships among people, organizations, and technologies" (Bietz et al., 2010: 245) devoted to rare diseases. Moreover, this allows a conceptualisation in which the material artifacts that constitute a regime of boundary objects - such as databases, expert systems or classification tools - are seen not only as collaboration-enabling mediators that can circulate between multiple communities, but also as resources that "can serve to establish and destabilize protocols themselves [and be] used to push boundaries rather than merely sailing across them", as Lee (2007: 308) powerfully suggests in her study of a multidisciplinary collaborative design of a museum exhibition.

In the next section, we use this understanding of the Rare Diseases Platform as a boundary infrastructure to explore how knowledge activities permeate the daily work of a large number of its members. We strive to show the active, generative characteristic that reveals itself in the infrastructural work performed by the involved parties. Star and Ruhleder (1996: 114) answered the question: "When is infrastructure?" by stating that "an infrastructure occurs when the tension between local and global is resolved". Our own answer aims at suggesting that, more often than not, a knowledge infrastructure occurs when the tension between local and global is reflexively and productively maintained.

\section{Inside the Database: the Material Embeddedness of Knowledge}

\section{Knowledge (at) Work}

In her social history of rare diseases, Caroline Huyard (2009: 475) insists on the fact that "the category of rare diseases was created with the very intention of restoring collaborative relationships between stakeholders who were unable to find common ground". Her work approaches rare diseases as a boundary object that came about in order to create mobilisation around a cause that is first and foremost analysed as "political" (Huyard, 2012). In our own study, we try to supplement this view, by focusing on the concrete, everyday work of heterogeneous engineering (Law, 1987) that is needed to sustain the category as a boundary object and keep it afloat. This leads us firstly to highlight the important role played by various forms of knowledge activities that are centrally organised around Orphanet's relational database, by focusing on the work of so-called "information scientists" (documentalistes scientifiques in French), who for one reason or another have to intervene in the "inner" workings of the database on a dayto-day basis. We then give an illustration of the way elements of the database are mobilised by other organisations in the Platform, focusing on how counsellors on the MRIS help line interact with Orphanet.

Information scientists at Orphanet are responsible for gathering information to "feed" the database, both by creating new entries and updating existing information. They can be found working individually, or in small teams, delving into external sources to find new or additional information about a disease, may it be through scientific publications, genetic databases, or websites listing experts, research laboratories, diagnostic centres and so on. They spend a good deal of time browsing online scientific databases such as PubMed, or querying Google, Google Scholar, and specialised search engines. The computer screens behind which they are busy browsing, reading, writing or talking to each other, typically display multiple windows, one of which might be open on the standard thesaurus of medical vocabulary (MeSH), another on an online catalogue of human genes and genetic disorders (OMIM), and occa- 
sionally a third window displaying a Wikipedia entry. These search activities allow the information scientists to complete and update fields in the Orphanet database through a dedicated in-house software interface, but also provides an opportunity to identify and take note of new diseases and resources that could be integrated in the future. In carrying out these tasks, Orphanet's information scientists are not simply looking for missing information through entirely routinised procedures, knowing in advance what they need to find and where. Rather, they are actively engaged in reading and interpretive activities, as well as operations to include and associate data from heterogeneous sources, which were not linked prior to their involvement. We see them for instance adding new types of materials to the database, such as hypertext links or detailed queries that will allow a user to find a collection of relevant scientific articles related to a specific disease within PubMed. This work requires familiarity with "database culture" - most often acquired on the job - and it is not limited to Orphanet's technical infrastructure, but extends more generally to mastering all existing specialised information sources in the field. Another common activity entailed by the need to "gather information" consists in identifying and interacting with various experts in order to enrol them as partners and help collect more information about a given disease. The information scientists thus spend a great deal of time trying to obtain data and requesting updates, by asking people to fill out forms, or appealing to European partners who can provide information through a shared online tool.

Information scientists at Orphanet also write - and get others to write - documents that will end up as electronic resources embedded in the texture of the database and the web portal. This concerns for instance "summaries", which form the centrepiece around which each disease entry and its related resources are arranged inside the database. The information scientists initiate first drafts, correct, edit, proofread, and distribute texts to experts and patient organisations in order to come up with, for example, articles for the general public or recommendations regarding "emergency procedures" for a given disease. One information scientist describes part of this process:
"We send these documents to associations and experts at the same time. Everything that is related to medical aspects is treated by the experts. But we have an item that is named 'Additional emergency and hospitalisation guidelines', which are meant to be handed by emergency physicians to teams receiving patients for hospitalisation. These are things that a medical expert will typically never think or write about, very simple and commonsensical things, like adapting the size of the bed for a patient with Marfan syndrome who measures two meters, you see? These are also things one must think about, and we ask patient associations to pay attention to these details and add them to the documents."

Finding the "right" expert - a specialist, one gathers, who is at the same time renowned in her field, well versed in the clinical aspects of rare diseases, and willing to devote time to write and sign a text for Orphanet - is a challenge that proved for a long time a major hurdle for the organisation. In 2006 , to mitigate the difficulty of getting experts involved in the writing process, Orphanet created a peer-reviewed scientific journal called the Orphanet Journal of Rare Diseases. From then on, this offered researchers an opportunity to publish their findings according to the canons of science, with the added advantage of indexation in the main databases (PubMed, Medline, ISI Web of Science, Google Scholar, Scopus, etc.) used by the information scientists in their work. The management of such distributed writing, which requires keeping track of the different versions and deadlines for a given text, relies on a host of memory practices (Bowker, 2005) and produces in turn an accumulation of various material traces: Excel spreadsheets, archives of email exchanges, printouts and so on. During this process of identifying, enrolling and assisting medical experts and patient associations in the production of texts, important choices are made that restate epistemic and political orientations and commitments, and affect what is present inside the database, and how this is presented in the various outputs.

Maladies Rares Info Services (MRIS) is another organisation part of the Platform that delivers information and provides support to people calling the help line with queries related to (potentially) rare diseases. We are immediately reminded 
of the importance Orphanet plays in these counsellors' activities by looking at their computer screens, which typically displays an Orphanet web page related to the disease or family of disorders the ongoing phone call seems to be about. Orphanet provides in this context one of the most reliable and comprehensive information sources for scientific, medical, healthcare and support dimensions of rare diseases. This allows MRIS counsellors to identify for example which hospital hosts the relevant expert centre for establishing or confirming diagnosis, which patient association can provide support, or to relay specific procedures for obtaining drug coverage. As one MRIS counsellor puts it:

\footnotetext{
"Thank God we have Orphanet, it's our main source of information! When Internet access is down or there is a problem with the database, we feel very destitute. I can't remember all the details about thousands of diseases, let alone all the different information related to them! [...] We had an in-house database before, but we have stopped maintaining and using it now that we use Orphanet documents."
}

This important reliance on Orphanet for counselling activities often raises specific issues. First and foremost, interactions on the help line rarely take the form of pure "information delivery" about a well identified disease entity. In many cases, people calling are preoccupied by health problems for which they (or a close relation) still haven't obtained a medical diagnosis. Moreover, as one can imagine, these interactions are fraught with emotional aspects, which entail considerations on the phrasing and content of rare disease descriptions in Orphanet documents, and how to manage potentially alarming information. This is well illustrated by the following statement made by another MRIS counsellor:

\footnotetext{
"Orphanet is highly ranked in search engine results. When people enter the name of a [rare] disease, chances are they'll come across a related page on Orphanet, and read it. But they still have questions and want to talk about it. So we have to deal with the reactions of people who read these documents... which can be useful, you know, to improve them... Because, there are at least some documents that in my opinion are problematic...
}

the way things are said, it's harsh sometimes.. Of course they need to be comprehensive, but sometimes it's not good to be too comprehensive. This is striking for example in some pathologies with prenatal diagnosis, which are very distressing situations. The person does not know her baby, no one has seen the baby, really... and the document describes a list of things that can be very distressing for people, among which some appear in only $1 \%$ of the cases."

Over the years, what was a strong collaboration between MRIS counsellors and Orphanet staff, taking place through weekly face-to-face meetings, declined to less frequent exchanges through email. MRIS participation to discussions concerning for instance which disease entities should come first in Orphanet's work priorities, based on their experience at the help line, slowly dwindled. In the space of a decade, most of the diseases that MRIS counsellors encountered in the course of their activity - typically the most frequent of rare diseases - had already been integrated to the database, and well documented, according to Orphanet's standards. One gets the impression that MRIS counsellors consider that over time, their growing reliance on Orphanet has come to the detriment of their active involvement with the organisation, and the taking into account of some of their specific concerns and forms of expertise.

\section{Infrastructural Inversion as Strategy and Practice}

Bowker (1994) has introduced the notion of "infrastructural inversion" as a methodological lens which allows the analyst to capture how things like databases and classification systems are embedded into the practices of collectives that share a common infrastructure. By bringing to the fore the mundane technical and organisational processes that sustain an infrastructure's operation, one can bring back to light important aspects that ordinarily tend to recede into taken-for-grantedness. Drawing on this insight in his masterful work on the climate knowledge infrastructure, Paul Edwards (2010: 20) argues that infrastructural inversion provides more than a methodological tool available to the ethnographer in the field. He finds that the scientists he studies also resort to this strategy as they negotiate infrastructural 
commitments, and that "infrastructural inversion is, in fact, fundamental to how scientists handle data". We contend that this argument is not limited to scientists, but holds true for many actors engaged in knowledge work of some kind. This can be empirically illustrated through observations of "classification meetings" that take place on a monthly basis at the Rare Diseases Platform.

In order for a rare disease entity to appear inside the relational database, it must at least be given a place in a biomedical classification, and be linked to a set of resources (a written definition, at the very least). During classification meetings, the Orphanet director, the scientific director, some information scientists, as well as invited members of the Platform gather to go over the entities whose creation in the database should be given priority, as well as those which, in relational database parlance, need to be "deleted", "disincluded" or "unlinked". Collective discussions and decisions rely on documents compiled during the abovementioned research phase, and take into account general clinical and scientific considerations, but also attend to more practical emergencies, based especially on a list of requests coming from other partners in the Platform or from scientists working worldwide on genes involved in certain rare diseases.

These meetings provide an occasion to witness how political, moral and epistemic principles are collectively debated, problematised and articulated with technical considerations. For example, the heading under which a disease will appear in the database (alongside a list of synonyms that link back to the main entry) is deemed crucial. Some proposed names don't make good candidates because they don't "sound" right, or look too complicated, prompting reactions such as: "You always need to think about the patient [...] A disease name is used when patients, doctors, and other people talk to each other, after all, not just fundamental researchers..." Other important matters are also addressed, such as the group in which a particular disease should be placed among the different available clinical and genetic classifications. Another topic pertains to the types of documents that should be produced: will just a summary do (but "even writing a summary involves touching everything in the database"), or is it a disease that "deserves a real text" and other resources to be added (links to scientific publications, lists of genes involved, etc.)? Should a particular disease be included in the database but left "mute", meaning that it will be recorded but not accessible via the web portal since it is not linked to any resource? Occasionally, for a host of reasons, some diseases need to be "dis-included": a single entity is split into two or more entries, each with its own resources. Finally, some diseases are deleted when, for example, they have remained unlabelled in the database for too long and no resources have been linked to them. Decisions in creating, including, deleting a disease, as well as managing the diversity of available resources - and their consequences for the database's very development - appear very tricky, because they have meaningful impacts everyone needs to be aware of. In the course of these meetings, those involved seek to reaffirm the priorities behind Orphanet's and the Platform's missions, as illustrated by the following arguments: "It is the clinical aspect that counts in the long run"; "It makes no sense to create a disease if you do not have a good text to go along with it"; "We need to be careful about this deletion, it would make no sense to lose knowledge!"

These vignettes underline the fact that making multiple perspectives on rare diseases converge in meaningful, compatible and efficient ways is not an easy task. As negotiations unfold, priorities are established and reaffirmed, and some values gain precedence. This results in specific ways of framing rare diseases being better represented than others, both on the private side of the database, and its public manifestation through the web portal. The way navigation through the Orphanet portal is entirely framed and constrained by disease entities is a case in point. Moreover, given the prevailing perspectives of the actors of the Platform, clinical considerations remain prominent, at the expense, for example, of etiological considerations. In performing this kind of categorical work, actors rely on the relational database, and discussions about its inner workings and evolution, as a fulcrum to articulate work processes within the boundary infrastructure. The database therefore appears in its dual character as means and end: the focus of 
people's work, it is the reason for which they work (to enhance and maintain the database); but as a work tool, it is also the instrument with which they strive to fit together scales, temporalities and outputs within the infrastructure.

Here then, we witness infrastructural inversion taking place for two main reasons. The first one has to do with the fact that gaining recognition and securing resources for database-related activities poses a genuine problem in terms of representing the work this involves and its outcomes. The various tasks required to collect, connect, edit or delete data - and the motives underpinning these activities - are often poorly understood, under-valued or even ignored, and end up being relegated to "mere" maintenance and updating activities. Infrastructural inversion, then, is a means to restore the complexity of these activities, and reaffirm their crucial role, by unfolding the heretofore invisible technical and organisational intricacies that sustain them (Star \& Strauss, 1999; Dagiral \& Peerbaye, 2012). The second reason is related to the fact that most actors we met were well aware of the provisional character of knowledge work, and recognised that the procedures one chooses to validate knowledge, the types of information one favours, the ways in which data are linked and presented all play a role in the kinds of knowledge that are given pre-eminence, which in turn shape forms of commitment and collective action. Infrastructural inversion, then, is also a strategy that partakes in the negotiation of hierarchies and priorities, generates controversies, reaffirms convictions, and carries weight in decisions. In this respect, we see infrastructural inversion happening not only when things break down and need to be repaired (Star \& Ruhleder, 1996) but also when the infrastructure needs to be updated, upgraded or extended, all activities that require some form of vigilance, maintenance and care (Denis \& Pontille, 2015).

\section{Beyond the Database: Caring for the Boundary Infrastructure}

\section{Keeping It Infrastructural: Maintenance and Extension}

The allocation of repair and maintenance work across the Platform brings to light a number of elements pertaining to what needs to be done in order for a boundary infrastructure to function satisfactorily for its constituency. This might be related for instance to the upgrading of electrical installations (e.g. setting up uninterruptible power supply units for safeguarding computer workstations) or computer network administration tasks - a consideration which highlights the need for infrastructural commitments to articulate and bridge a varied set of technological requirements (Vertesi, 2014). As one of the organisations staffed with the most "computer specialists", Orphanet was particularly solicited in this respect, much to the dismay of the concerned individuals, who regularly complain about how poorly boundaries between the work of programmers, web developers, database managers, and computer systems administrators are understood and respected across the whole platform. An additional illustration is provided by the many tribulations of Orphanet's hardware servers, housing working versions of the relational database. The story, as recounted by one of the database managers, exemplifies challenges related to the work of building conventions and of establishing stable relations with things, especially in a context of organisational and institutional fragility (high staff turnover, frequent relocations and so on):

"[Until the early 2000s] our machines were hosted at Infobiogen [a now defunct French bioinformatics resource centre]. Then Infobiogen closed down, and our machines wandered about a bit for some time. We found a temporary solution as 'guests' of the Paris IV University, but the accommodation was not on par with what we had before, and we needed more resources. Then we had the opportunity of being hosted within Inserm's DSI [the general IT Systems Department], which means we integrated a more 'normative' environment. And this is far from being insignificant, from a cultural perspective. Because at Orphanet, from the very beginning, we have had a very tinkering, hands-on approach to things - in the best sense. [...] When you arrive in an 
environment like the DSI, things are different, there are dedicated teams, infomanagement services and so on... You can't have remote access to your server in exactly the same way. You need to log in with credentials, fill forms explaining what, why... It's very tedious and time-consuming. But at the same time, when you don't do things this way, you can run into problems... Like getting hacked by a Turkish pirate [laughs] because the update was not done properly, because the engineer... well the engineer was leaving [Orphanet] and had not done things correctly, and the architecture was not strong enough. These things happen. And how you need to act in these situations, is by implementing a number of processes that will entrench action independently of individuals. Because the problem is, individuals come and go, and it is dangerous to have a system whose processes depend entirely on individuals. It's great having people, you need motivated people, that's for sure, but you can't rely only on them, because you can put yourself in danger for trivial reasons."

The division of labour across organisations points out the tensions related to forms of taken-forgrantedness or invisibility, and the distributed ways of managing and taking care of shared spaces, tools, technologies and perspectives, further emphasising the intensely relational nature of infrastructure. However this dimension of an infrastructure's daily life refers to only one aspect of what caring about any boundary infrastructure is actually about. Building upon work dedicated to the study of large technical systems, and especially cities, Steven Jackson (2014: 231) suggests that:

\footnotetext{
"foregrounding maintenance and repair as an aspect of technological work invites not only new functional but also moral relations to the world of technology. It references what is in fact a very old but routinely forgotten relationship of human things in the world: namely, an ethics of mutual care and responsibility."
}

If maintenance and repair usually sends us back to the present and its urgency, here above all else the care of things reflects the necessity of anticipation, of thinking about future developments and what can be gathered under the term of "extension", referring to the work of infrastructuring foresight and extensibility. Maintenance work as "care" therefore does not only equate with maintaining the installed base in a good state of upkeep or repair: what is at stake here has to do with ensuring continuity and reconfiguration, robustness and flexibility, as technologies and commitments evolve, and the transformations of initial projects call forth new versions of the system, and generate new meanings for collective endeavour. One good example of this lies in Orphanet's efforts, dating from around 2005 onwards, to initiate developments in order to interface its database with other online reference resources in the biomedical world, such as SwissProt, OMIM, MedDRA, Snomed, MeSH and the catalogue and index of French-language medical sites (Cismef) maintained by the Rouen University Hospital Centre. In order to exist with ever greater relevance in this landscape of health information and biomedical research, and to ensure the visibility of rare diseases therein, Orphanet's development strategy started giving crucial importance to this work of extension, interconnection and standardisation. Maintenance work therefore tended towards the anticipation and construction of extensions rendered necessary by the shifts within the boundary infrastructure. In order to address concerns related to connectability and extension in the project's orientations, which remain largely unpredictable due to uncertainties regarding future technological trends, the technical team needs to embed this work in the standardisation processes at play in the IT worlds. From this point of view, the tension between standardisation and flexibility which is characteristic of many knowledge infrastructures becomes visible (Hanseth et al., 1996). This is not so much a case of interpretive flexibility as what could be termed flexibility "by design", intended to fulfil the promise of securing data and their relations irrespective of the paths subsequently taken.

\section{Negotiating New Boundaries}

The observation of meetings devoted to a project on "multi-technology health services" provides an opportunity to grasp the fragile balance between "legacies" of past versions of the database and the promise of "shareable ontologies" afforded by the semantic web, pointing to potentially new 
ways of interconnecting with external databases as well as generating classifications. The development of projects such as these requires interfacing entire parts of the database with other bases, each with its own history, made up of technical choices, norms, standards and particular specifications, which must be taken into account for effectiveness. At the same time, the normalisation and standardisation work inherent to database management systems as a field is largely geared towards such objectives of integration, fusion and interoperability. A consultant specialised in the domain of biomedical databases has been advising the Orphanet team on this matter since the organisation first purchased a Sybase licence in 1996. Gathered around whiteboards displaying hand-drawn graphic representations of the database, the consultant and four of the members of the IT team regularly remind newcomers in their discussion of why a given element of the database is like that "for historical reasons", or justify the nature of the relations between elements inside a data table.

In order to ensure its financial stability, and renew its relevance as a member of the Platform, Orphanet has also gradually been led to build a number of commercial and public services designed to promote its data, supplying specialised extractions of its database for the worlds of clinical and fundamental research as well as the pharmaceutical industry. This has entailed establishing new working priorities in order to focus on disease entities that were of topmost relevance to biomedical institutions and drug companies (namely diseases for which ongoing clinical trials, drug development or research projects were available).

Furthermore, as from 2010, and as a consequence of the Platform's involvement in the European Commission Expert Group on Rare Diseases, the disease classifications produced within Orphanet gained recognition as a central reference for the inclusion of rare diseases into the next revision of the International Classification of Diseases (ICD-11) maintained by the World Health Organisation (WHO). Bowker and Star (1999: 107-108) had already noted in their analysis of the ICD as a constantly evolving boundary infrastructure how much this central tool depends on the interaction between diverse preexisting infrastructures (databases, classification systems, national and international institutions). At the level of the Platform, new commitments and reconfigurations had therefore to be negotiated, in order to ensure that the database would be able in the long run to supply the WHO with classifications and ontologies in a novel form, with a view to integrating rare diseases into the ICD. This task required that members of the boundary infrastructure devote time and energy to reshape the classifications and annotations embedded in the relational database, in order to ensure their compliance with the ICD requirements. One immediate consequence of this was a slowing down of the general rate at which the various electronic resources associated to disease entities were being added or updated in the relational database.

These examples highlight the dynamics of belonging, inclusion (and sometimes exclusion) that go along with infrastructures as "invested forms". They also suggest that oftentimes investment in form is not a process that happens at the outset, as a prerequisite that will be followed by periods of relatively unproblematic coordinated action. Rather, as the boundaries of the infrastructure shift - being both a cause for and a consequence of investment in form - this in turn calls for further adjustments: investment in form builds on and reconfigures previous investments. This is made manifest through the intertwined regimes of care that are part and parcel of maintaining and reconfiguring a boundary infrastructure like the one represented by the Rare Diseases Platform.

\section{Conclusion}

Exploring the life and work of the knowledge infrastructure that constitutes and is constituted by the European rare diseases community, one cannot help but being struck by its dual nature, as something which alternates between being "taken for granted" and "problematic", "learned as part of membership" and open to negotiation. Both from an external perspective, and from the insider outlook of the actors of the Rare Diseases Platform, infrastructure embodies both an achievement that manages to represent rare diseases and its multiple challenges, and a project 
which in its very form is fraught with enormous fragility and uncertainty - which in turn weighs upon the work of those involved and never ceases to question their collective involvement. This constant shift between taken-for-grantedness and problematicity, between learning and calling into question, is probably a more general feature of knowledge infrastructures, especially when they exist as a modality of boundary infrastructures encompassing multiple causes. In particular, the fragility of commitments as well as the work required to maintain the meanings of collective action play an important role in this essential tension. In this respect, the impossibility to reach a state of completion, given the levels of flexibility and open-endedness required, is perhaps a key component of a knowledge-in-the-making-oriented infrastructure.

Our ethnographic study of the Rare Diseases Platform therefore provides insights that further our understanding of knowledge production issues in projects that are not limited to scientific outputs, but also include explicit political and moral objectives. In this paper we have shown how what counts as knowledge is negotiated between the participants of a boundary infrastructure, which relies centrally on a relational database situated at the crossroads of a large and complex network of individuals, institutions and practices. Epistemic, political and ethical commitments are materially enacted within the sociotechnical framework provided by the database through an ecology of work practices that shape ways of knowing, living with, and fighting social ignorance of, rare diseases.

We have also analysed infrastructural inversion as a practice that members of the boundary infrastructure resort to in order to negotiate the meanings of their collective action. It allows them to articulate knowledge-related activities with other forms of mobilisation, that do not necessarily rely on the database itself, and their active involvement in its inner workings. Infrastructural inversion allows the tension between local implication at the level of the database and global engagement for rare diseases as a political cause to be reflexively and productively managed. We contend that the existence of the Rare Diseases Platform as a boundary infrastructure ultimately rests on this process.

Furthermore, in the empirical case under scrutiny, what is at stake in the building and maintaining of a boundary infrastructure devoted to the cause of rare diseases extends well beyond issues of coordination or scientific collaboration. As Keating and Cambrosio (2003: 324) argue: "insofar as they embody regulations and conventions of equivalence, exchange, and circulation [...], platforms are not simply one among many forms of coordination that include networks; rather, they account for the generation of networks or, at the very least, they are a condition of possibility for the very existence and transformation of networks". The Rare Diseases Platform as a boundary infrastructure manifests itself as a specific network for representing rare diseases, that reflects situated material cultures and political agendas, and is generated through particular investments in form. These investments evolve in time, as technologies change, and different projects are carried out (Karasti et al., 2010). Consequently, infrastructural commitments need to take account of past legacies and anticipate new requirements and visions. The shape of the boundary infrastructure as a whole is thereby in a state of continued reconfiguration.

The perspective adopted in this article tends to play down the extended involvement of Orphanet and members of the Platform in other spaces where research on and management of rare diseases take place, such as the European Union Committee of Experts on Rare Diseases, the European Medicines Agency, or the International Rare Diseases Research Consortium. However, we suggest here that what happens in these arenas must be explored and understood in the light of the knowledge work being produced within the boundary infrastructure. How curators tackle sociotechnical issues inside and beyond the database ultimately shapes the broader agenda of rare disease policy. 


\section{Notes}

1 http://www.orpha.net/

\section{Acknowledgements}

This research was in part supported by the lle-de-France Regional Council (Institution-Citizen Partnerships for Research and Innovation grant, PICRI 2008-2011). We warmly thank the special issue editors and three anonymous referees, whose comments and suggestions were most helpful for improving this paper. We are especially grateful to Madeleine Akrich, Florence Millerand, Jérôme Denis and David Pontille for providing opportunities and food for thought to keep conversations about infrastructures alive.

\section{References}

Aymé S \& Rodwell C (eds) (2013) 2013 Report on the State of the Art of Rare Disease Activities in Europe. European Union Committee of Experts on Rare Diseases. July 2013.

Bietz MJ, Baumer EPS \& Lee CP (2010) Synergizing in Cyberinfrastructure Development. Computer Supported Cooperative Work 19: 245-281.

Bowker GC (1994) Science on the Run: Information Management and Industrial Geophysics at Schlumberger, 1920-1940. Cambridge, MA: MIT Press.

Bowker GC (2000) Biodiversity Datadiversity. Social Studies of Science 30(5): 643-683.

Bowker GC (2005) Memory Practices in the Sciences. Cambridge, MA: MIT Press.

Bowker GC, Baker KS, Millerand F \& Ribes D (2010) Towards Information Infrastructure Studies: Ways of Knowing in a Networked Environment. In: Hunsinger J, Klastrup L \& Allen M (eds) International Handbook of Internet Research. Dordrecht: Springer, 97-117.

Bowker GC \& Star SL (1999) Sorting Things Out: Classification and Its Consequences. Cambridge, MA: MIT Press.

Dagiral E \& Peerbaye A (2012) Les mains dans les bases de données : connaître et faire reconnaître le travail invisible. Revue d'anthropologie des connaissances 6(1): 191-216.

Dagiral E \& Peerbaye A (2013) Voir pour savoir. Concevoir et partager des "vues" à travers une base de données biomédicales. Réseaux 178-179: 163-196.

Denis J \& Pontille D (2015) Material Ordering and the Care of Things. Science, Technology \& Human Values 40(3): 338-367.

Dutton WH \& Jeffreys PW (eds) (2010) World Wide Research. Reshaping the Sciences and Humanities. Cambridge, MA: MIT Press.

Edwards PN (2010) A Vast Machine. Computer Models, Climate Data, and the Politics of Global Warming. Cambridge, MA: MIT Press.

Gieryn T (1983) Boundary-Work and the Demarcation of Science From Non-Science: Strains and Interests in Professional Ideologies of Scientists. American Sociological Review 48(6): 781-795.

Hanseth O, Monteiro E \& Hatling M (1996) Developing information infrastructure: The tension between standardization and flexibility. Science, Technology \& Human Values 21(4): 407-426.

Hilgartner S (1995) Biomolecular Databases: New Communication Regimes for Biology? Science Communication 17(2): 240-263.

Hine C (2006a) Databases as Scientific Instruments and Their Role in the Ordering of Scientific Work. Social Studies of Science 36(2): 269-298. 
Hine C (ed) (2006b) New Infrastructures for Knowledge Production: Understanding EScience. Hershey: Information Science Publishing.

Huyard C (2009) How did uncommon disorders become "rare diseases"? History of a boundary object. Sociology of Health and IIIness 31(4): 463-477.

Huyard C (2012) Rare. Sur la cause politique des maladies peu fréquentes. Paris: Presses de l'EHESS.

Jackson SJ (2014) Rethinking Repair. In: Gillespie T, Boczkowski PJ \& Foot KA (eds) Media Technologies. Essays on Communication, Materiality, and Society. Cambridge, MA: MIT Press, 221-307.

Knorr Cetina K (1999) Epistemic Cultures. How the Sciences Make Knowledge. Cambridge, MA: Harvard University Press.

Karasti H, Baker KS \& Millerand F (2010) Infrastructure Time: Long-term Matters in Collaborative Development. Computer Supported Cooperative Work 19: 377-415.

Keating P \& Cambrosio A (2003) Biomedical Platforms. Realigning the Normal and the Pathological in LateTwentieth-Century Medicine. Cambridge, MA: MIT Press.

Law J (1987) Technology and Heterogeneous Engineering: The Case of Portuguese Expansion. In: Bijker W, Hughes T \& Pinch T (eds) The Social Construction of Technological Systems. Cambridge, MA: MIT Press, 111-134.

Lee CP (2007) Boundary Negotiating Artifacts: Unbinding the Routine of Boundary Objects and Embracing Chaos in Collaborative Work. Computer Supported Cooperative Work 16: 307-339.

Leonelli S (2013) Integrating Data to Acquire New Knowledge: Three Modes of Integration in Plant Science. Studies in the History and Philosophy of the Biological and Biomedical Sciences 44(4): 503-514.

Leonelli S (2015) What Counts as Scientific Data? A Relational Framework. Philosophy of Science 82(5): 810-821.

Miller CA \& Edwards PN (eds) (2001) Changing the Atmosphere. Expert Knowledge and Environmental Governance. Cambridge, MA: MIT Press.

Millerand F (2011) Le partage des données scientifiques à l'ère de l'e-science : l'instrumentation des pratiques au sein d'un collectif multidisciplinaire. Terrains \& Travaux 18: 215-237.

Millerand F \& Bowker GC (2009) Metadata Standards. Trajectories and Enactment in the Life of an Ontology. In: Lampland M \& Star SL (eds) Standards and Their Stories. How Quantifying, Classifying, and Formalizing Practices Shape Everyday Life. Ithaca and London: Cornell University Press, 149-176.

Olson GM, Zimmerman A \& Bos N (eds) (2008) Scientific Collaboration on the Internet. Cambridge, MA: MIT Press.

Parker JN, Vermeulen N \& Penders B (eds) (2010) Collaboration in the New Life Sciences. Farnham \& Burlington: Ashgate Publishing Company.

Star SL (2010) This is Not a Boundary Object: Reflections on the Origin of a Concept. Science, Technology \& Human Values 35(5): 601-617.

Star SL \& Griesemer JR (1989) Institutional Ecology, "Translations" and Boundary Objects: Amateurs and Professionals in Berkeley's Museum of Vertebrate Zoology, 1907-39. Social Studies of Science 19(3): 387-420.

Star SL \& Ruhleder K (1996) Steps Towards an Ecology of Infrastructure: Design and Access for Large Information Spaces. Information Systems Research 7(1): 111-134.

Star SL \& Strauss A (1999) Layers of Silence, Arenas of Voice: The Ecology of Visible and Invisible Work. Computer Supported Cooperative Work 8: 9-30.

Strasser B (2011) The Experimenter's Museum: GenBank, natural history, and the moral economies of biomedicine. Isis 102(1): 60-96. 
Thévenot L (1984) Rules and Implements: Investment in Forms. Social Science Information 23(1): 1-45.

Thévenot L (1986) Les investissements de forme. In Thévenot L (ed) Conventions économiques. Paris: Presses Universitaires de France, 21-71.

Thévenot L (2009) Postscript to the special issue Governing Life By Standards: A View from Engagements. Social Studies of Science 39(5): 793-813.

Vertesi J (2014) Seamful Spaces: Heterogeneous Infrastructures in Interaction. Science, Technology \& Human Values 39(2): 264-284. 